\title{
Head Circumference and Brain and Hippocampal Volume after Severe Traumatic Brain Injury in Childhood
}

\author{
ROBERT C. TASKER, CLAIRE H. SALMOND, AMBER GUNN WESTLAND, ALONSO PENA, \\ JONATHAN H. GILLARD, BARBARA J. SAHAKIAN, AND JOHN D. PICKARD \\ Department of Paediatrics [R.C.T., A.G.W.], Department of Psychiatry [C.H.S., B.J.S.], Department of \\ Neurosurgery [A.P., J.D.P.], Department of Radiology [J.H.G.], Wolfson Brain Imaging Centre [R.C.T., \\ C.H.S., A.G.W., A.P., J.H.G., B.J.S., J.D.P.], Addenbrooke's Hospital, Cambridge, CB2 2QQ, United \\ Kingdom
}

\begin{abstract}
ABST
Vulnerability of the hippocampus to traumatic brain injury (TBI)
in adults is related to severity of injury and white matter atrophy.
The objectives of this study were to determine features of anthro-
pometry and cerebral morphometry late after TBI in childhood and
to assess whether hippocampal volume is related to severity of
initial ictus and changes in white matter at follow-up. Thirty-three
patients underwent magnetic resonance imaging 4.9 y after severe
TBI that necessitated intensive care; 23 had mechanical ventilation
and intracranial pressure monitoring longer than 3 d. Magnetic
resonance imaging analyses included volume of brain, hemisphere,
ventricles, and hippocampal and perihippocampal regions; spatial
distribution of voxel-based morphometry differences in white mat-
ter; and eigenvalues of diffusion tensor imaging diffusivity. Patients
with longer intensive care ictus had smaller-than-expected occipit-
ofrontal head circumference. Eight of these, identified by voxel-
based morphometry, had periventricular white matter loss and
smaller-than-expected brain volume for OFC, suggesting "atrophy";
the remainder had expected volume for a smaller OFC, suggesting
"growth disturbance." Ninety-three percent of the variation in right
hippocampal volume was accounted for by factors related to sever-
ity of injury and white matter atrophy. It is concluded that anthro-
pometry and cerebral morphometric measurements late after severe
\end{abstract}
A key factor in preserving cognitive abilities during aging is brain growth during childhood $(1,2)$. Larger head size is associated with better performance, and, in adults, a difference as small as 1.3 $\mathrm{SD}(\sim 2 \mathrm{~cm})$ is of major significance. It is also suggested that factors that promote brain growth may protect against cognitive decline (2). However, a corollary to this idea must also be the potential effect of impaired growth in child-

Received June 25, 2004; accepted November 30, 2004.

Correspondence: R.C. Tasker, M.D., Department of Paediatrics, Box 116, Clinical School, University of Cambridge, Addenbrooke's Hospital, Hills Road, Cambridge, CB2 2QQ, UK; e-mail: rct31@ hermes.cam.ac.uk.

Supported by the Medical Research Council (UK), The Frances and Augustus Newman Foundation, and Wellcome Trust.

DOI: 10.1203/01.PDR.0000169965.08854.25
TBI in childhood provides useful outcome data and indicate that, despite adequate growth in stature, effects of TBI on brain growth and hippocampal volume may extend into adulthood. (Pediatr Res 58: 302-308, 2005)

BSA, body surface area

\section{Abbreviations}

DTI, diffusion tensor imaging

DW, diffusion weighted

GCS, Glasgow Coma Scale

ICP, intracranial pressure

ICV, intracranial volume

OFC, occipitofrontal head circumference

ROI, region of interest

SDS, SD score

SPGR, spoiled gradient echo

SPM, statistical parametric mapping

TBI, traumatic brain injury

VBM, voxel-based morphometry

VBR\%, ventricular brain ratio hood and risk for lesser cognitive function throughout adulthood, with detrimental implications in old age.

Traumatic brain injury (TBI) is relatively common in children and adolescents (3), and in recent years, there has been much work on the close relationship between findings on magnetic resonance imaging (MRI) and functional and behavioral outcomes. The hippocampus and white matter have been a particular focus. For example, in adults who survive TBI, MRI findings show that the degree of hippocampal atrophy is related to severity of initial injury (4) and subsequent white matter atrophy (5). In children, however, only a trend ( $p=$ 0.09 ) toward smaller right hippocampal volume has been found in more severe cases (6).

Hippocampal volume and its relations can serve as a "bioassay" of previous or ongoing pathology and development. For 
example, the hippocampus is a temporal lobe grey matter structure that grows during adolescence (7). It is susceptible to deafferentation secondary to generalized cortical cell loss resulting from direct injury; alternatively, this may result from loss of inputs as a result of necrosis of the perihippocampal area, a consequence of raised intracranial pressure (ICP). Finally, it is a structure that is selectively vulnerable to systemic metabolic derangement (8). The objective of this study was to consider the interaction among severity of TBI in childhood, white matter pathology, growth anthropometry, and hippocampal atrophy.

\section{METHODS}

Recruitment and clinical characterization. The Institutional Review Board for human studies (ethics review committee) of the Cambridge University Teaching Hospitals Trust approved this study, and informed consent was obtained from all participants and their families. All participants were survivors of severe TBI that had necessitated endotracheal intubation, mechanical ventilation, and admission to our pediatric intensive care unit during the 1990s. In all potential participants, a review of their acute ictus was gained from the patient record, investigations, monitoring, and treatment. These data included age at injury, postresuscitation, preintubation Glasgow Coma Scale (GCS) score (9), and whether neurosurgery was performed. Acute imaging was used to identify those with focal findings and skull fracture. When there was evidence of laterality, the side with predominant abnormality was considered to be the side with most injury. This blinded evaluation was based on the side of the head with intracranial blood (including contusions, hematoma, and subarachnoid); differential hemisphere swelling in which one hemisphere was more severely affected than the other, usually the one ipsilateral or subjacent to hemorrhage; and the site of skull fracture. Exclusion criteria for this study were previously diagnosed neuropsychiatric disorder, more than one hospitalization for TBI, status epilepticus during initial ictus, subsequent epilepsy or anticonvulsant therapy, or developmental disorder.

All 33 participants were assigned, a priori, to a severe TBI non-ICP or TBI ICP group. This categorization was based on duration of mechanical ventilation during the acute ictus, and the cut-off used was $3 \mathrm{~d}$ because patients with an insignificant level of ICP are removed from mechanical ventilation within this period. Twenty-three participants were in the $>3 \mathrm{~d}$ ICP group; all of these underwent ICP monitoring, and all received therapy for raised ICP, which in our practice is instituted when the level is $>20 \mathrm{~mm} \mathrm{Hg}$ (10). The demographic features of these groups did not differ in regard to age at injury, proportion male, or GCS.

At the time of MRI, height, weight, and head circumference [occipitofrontal circumference $(\mathrm{OFC})]$ were measured by a single observer using standard procedures (11). Age- and gender-specific SD scores (SDS) for all measurements were calculated using UK reference data (12). In participants who were older than the reference range for OFC, the SDS was calculated using the limits of the normal data. (This manipulation would tend to underestimate any difference between our groups.) Also, body mass index ([height in $\mathrm{m}] /[$ weight in $\mathrm{kg}]^{2}$ ) was converted into SDS, and body surface area (BSA) was calculated using standard tables (13).

MRI methods. MRI was performed on a Bruker Medspec 30/100 spectrometer (Bruker Medical, Etlingen, Germany) attached to an Oxford 3.0-T, 910-mm bore whole-body, actively shielded magnet (Oxford Magnet Technology, Oxford, UK). A multioblique three-dimensional spoiled gradient echo (SPGR) sequence was acquired using a repetition time of $20 \mathrm{~ms}$, an echo time of $5 \mathrm{~ms}$, a flip angle of $20^{\circ}$, a field of view of $25.6 \times 25.6 \times 25.6 \mathrm{~cm}$, and matrix size of $256 \times 256 \times 128$ (giving a spatial resolution of $1 \times 1 \times 2 \mathrm{~mm}$ ).

Diffusion tensor MRI. Diffusion tensor MRI (DTI) was performed using a standard single-shot, spin echo, echo planar imaging (EPI) pulse sequence, inserting a pair of diffusion weighted (DW) Stejskal-Tanner rectangular gradient pulses in it (14). The duration of the DW gradient pulses was $21 \mathrm{~ms}$, and their temporal spacing was $66 \mathrm{~ms}$. The DTI protocol consisted of 63 acquisitions. The DW gradients were applied along 12 noncollinear spatial directions arranged uniformly (15). For each direction, five DW images were acquired, each corresponding to $a$ different $b$ value (14). These five $b$ values were distributed equidistant in the interval $0-1570 \mathrm{~s} / \mathrm{mm}^{2}$, with $1570 \mathrm{~s} / \mathrm{mm}^{2}$ corresponding to optimum noise performance for a two-point apparent diffusion coefficient measurement $(15,16)$. The adverse effects of eddy currents on single-shot DW EPI (17) were eliminated efficiently by a robust adjustment of the preemphasis unit of the system (18). Multislice imaging was performed with eight to 12 contiguous slices in the near axial plane, with 5-mm-slice thickness and $25-\mathrm{cm}$ field of view. The acquisition matrix was $128 \times 128$, and sampling dwell time was $5 \mu \mathrm{s}$. Asymmetric k-space coverage was performed along the phase encode direction ( $24 \%$ of the data acquired before reaching the centre of k-space). The echo time was $106 \mathrm{~ms}$, and the repetition time was $5070 \mathrm{~ms}$. No other intermediate-processing step, such as image realignment or correction (as a result of eddy current-induced distortions) was required.

Volumetrics. All SPGR images were transferred to an offline workstation for postprocessing. One investigator, who was blinded to the participant group and information, made the volumetric measurements using ANALYZE software (Mayo Foundation, Rochester, MN). Reproducibility, as measured by intraclass correlation coefficient, was $>95 \%$. Previously reported methods were used for the assessment of intracranial volume (ICV) (19), hemisphere volume (20), and ventricular volume (21). Brain tissue volume was calculated from the difference between ICV and ventricular volume. Ventricular brain ratio $(\mathrm{VBR} \%)$ was calculated as follows: $\mathrm{VBR} \%=100 \times$ [ventricular volume]/[ICV] (22). Hemisphere VBR\% was calculated using the hemisphere volumes. Perihippocampal volume-defined as the sum of the main cortical inputs that come via the entorhinal cortex to the hippocampus and including entorhinal, perirhinal, and parahippocampal areas (23) — was measured with the SPGR slices reorientated orthogonal to the longitudinal axis of the right hippocampus. Images were viewed in the coronal plane, with a final slice thickness of $0.86 \mathrm{~mm}$ and magnified $400 \%$ using bilinear interpolation. A digital stylus and MEDx 3.4 software (Sensor Systems, Sterling, VA) was used to trace regions of interest (ROIs) from which volume measurements were subsequently determined by multiplying ROI area by the slice thickness. The anatomical boundary of the hippocampal formation was defined as a composite of the following regions: cornu ammonis subfields CA1 to CA4, the dentate gyrus, the subiculum and presubiculum, and the amygdalohippocampal transition area. The boundary rostrally, separating the hippocampus from the amygdala, was a combination of the alveus and the lateral ventricle. The lateral ventricle also served as the lateral boundary. Medially, the entorhinal cortex bordered the hippocampus, more caudally; posterior to the uncus, the boundary was the edge of the temporal lobe. The caudal limit extended to include the last slice in which the hippocampus was distinct from the fornix. The perirhinal region was defined as the grey matter surrounding the collateral sulcus, excluding a small medial portion that belongs to the entorhinal cortex. The rostral limit was located $2 \mathrm{~mm}$ anterior to the frontotemporal junction, and the caudal limit was $3 \mathrm{~mm}$ posterior to the end of the uncus. The collateral sulcus tends to vary in form. When it bifurcated, the entire bifurcation was included until the split was complete, at which point only the medial branch of the sulcus was included. The entorhinal area extends from the frontal-temporal junction to $2 \mathrm{~mm}$ caudal to the uncus. The rostral boundary was marked dorsally by the amygdala and the shallow sulcus semiannularis. When the sulcus semiannularis was not visible, the level of the uncal hippocampus marked the rostral boundary. Ventrally and laterally, the entorhinal cortex extended to the surface of the medial bank of the collateral sulcus, where it bordered the perirhinal cortex along the anteroposterior extent. The parahippocampal area was defined as both banks of the collateral sulcus together with the tissue ventral to the presubiculum. The rostral limit was the end of the entorhinal and perirhinal cortices, and the caudal limit was the beginning of the calcarine fissure.

Voxel-based morphometry. The three-dimensional data sets were analyzed in Statistical Parametric Mapping (SPM) 99 software (Wellcome Department of Cognitive Neurology, London, UK). Each scan was normalized to a standardised template (24). The data were normalized by global grey matter; this is a fundamental component that accounts for any differences among subjects that are simply due to differences in brain size. The images were segmented using a Bayesian algorithm (25), and continuous probability maps were produced whereby the values correspond to the posterior probability that the voxel belonged to the grey matter partition. White and grey matter segmented images were smoothed with $12-\mathrm{mm}$ isotropic Gaussian kernels that render the voxel values an index of the amount of grey (or white) matter per unit volume under the smoothing kernel.

Each individual from the ICP group was compared against the entire non-ICP group. Use of such unbalanced designs in SPM has been validated at $12 \mathrm{~mm}$ (26). Inferences from SPM were made at statistical threshold levels corrected for multiple comparisons across the entire brain.

Analysis of diffusivity. DTI axial scans were transferred to an offline workstation for postprocessing. One investigator, who was blinded to the participant group and information, selected each hemisphere ROI systematically from an axial slice at a level just above the corpus callosum and ventricle lateral horns (usually the penultimate axial slice). Four participants with slices that included ventricular space, because of ventriculomegaly, were excluded from this part of the analysis. The hemisphere ROI "object map" was selected by outlining the interhemispheric fissure and the cortical surface of each hemisphere. An individual object map was created for each hemisphere in each 
participant. Intraclass correlation coefficients for mean and SD of the ROI (left and right hemisphere) object maps ranged from 80 to $99 \%$.

The diffusion tensor diffusivity eigenvalues and eigenvectors were estimated for all voxels (27). Eigenvalues were sorted in order of decreasing magnitude for each voxel $\left(\lambda_{1}>\lambda_{2}>\lambda_{3}\right)$, with $\lambda_{1}$ representing the diffusivity along the primary diffusion direction $\epsilon_{1}$. The second and third largest eigenvalues $\left(\lambda_{2}\right.$ and $\left.\lambda_{3}\right)$ represented the diffusivities along directions that were perpendicular to the primary direction and to each other. Mean values for individual whole-hemisphere ROIs were used in the analyses.

Statistical analyses. Analyses were carried out using JMP Statistical Discovery Software (SAS Institute, Cary, NC). Parametric statistics were used because the distribution of the data did not violate assumptions of normality. To minimize false positives resulting from multiple tests, multivariate ANOVA (MANOVA) was used to determine whether the non-ICP and ICP groups had different patterns in 1) anthropometry and whole-brain morphometry and 2) hemisphere subregions and structure. Follow-up one-way ANOVA was run using grouping as the independent variable. When tests of equal variances revealed that the group variances were significantly different, the Welch ANOVA for the means was used in place of the usual ANOVA. Post hoc, between-group differences (taking account for multiple comparisons) was tested using Tukey-Kramer HSD with significance at $p<0.05$. Dependent variables that exhibited statistical significance $(p<0.05)$ or trend $(p<0.10)$ were assessed further in multiple regression analyses to examine confounding effects or interactions.

Analyses were undertaken on raw and corrected data. Brain and hemisphere volumes that were corrected for OFC were calculated by multiplying the measured volume by a factor, whereby the $f_{\mathrm{OFC}}=$ [mean OFC for entire population $]^{3} /[$ observed OFC for the participant] (3). Hippocampal and perihippocampal volumes that were corrected for hemisphere volume-from which they were a part-were calculated by multiplying the measured volume by a factor, whereby $f_{\mathrm{HC}}$ or $\mathrm{f}_{\mathrm{PHR}}=$ [mean hemisphere volume for entire population, left or right]/[observed hemisphere volume for the participant, left or right] (22).

\section{RESULTS}

The participants in this study had TBI at the age of 9.3 (4.0) years (mean, SD) and underwent MRI at age 15.1 (3.9) years, on average 4.9 y after injury. Seventeen of 23 participants in the severe TBI ICP group had mainly right-sided injury at the time of acute ictus; 13 of these 17 also had an ipsilateral skull fracture. Whole-brain VBM showed that these acute injuries were associated with later regional abnormalities: significant differences were found in eight of 23 ICP participants compared with the non-ICP group (hypothesis test for proportions, 2.22 SD difference; $p=0.036$ ). Only one of these eight underwent neurosurgery (Table 1). In five of these participants, VBM findings showed difference predominantly in the periventricular white matter (Fig. 1). In the remaining three participants, differences were distributed peripherally. Because one third of the ICP group had such white matter difference, all further analyses were performed taking account of this subgrouping in the ICP group, i.e. no VBM difference, and VBM difference.

Anthropometry and brain morphometry. In the ICP group, there was a reduction in OFC that could not be accounted for by any reduction in height or body size. For example, MANOVA with OFC SDS ( $\left.\mathrm{OFC}_{\mathrm{SDS}}\right)$ and BSA or body mass index SDS (summary measures of body size) as dependent variables shows disproportionately smaller OFC in the ICP group (Wilk's $\lambda$ 0.67, $F=15.3, p=0.0005$ ). Further MANOVA with patient group as a main effect and with $\mathrm{OFC}_{\mathrm{SDS}}$, corrected brain volume, and $\mathrm{VBR} \%$ as dependent variables shows again a significant effect of ICP grouping (Wilks $\lambda 0.62, F=8.14, p=0.002$ ) and also an interaction between this grouping and the cerebral parameters assessed (Wilks $\lambda 0.45, F=6.47, p=0.0003$ ). The follow-up ANOVA confirms that $\mathrm{OFC}_{\mathrm{SDS}}$ was disproportionately smaller in the ICP participants when body shape and size were considered.

On inspection of the data in Table 2, there are two separate brain morphometry findings in the ICP participants. In the subgroup without VBM-identified differences, the data suggest smaller $\mathrm{OFC}_{\mathrm{SDS}}(p<0.05)$ but brain volume corrected for head size similar to that observed in the non-ICP participants (i.e. no evidence of atrophy but a small head and appropriate volume suggesting growth disturbance). In the subgroup with VBM-identified brain tissue difference, there is also smaller $\mathrm{OFC}_{\mathrm{SDS}}(p<0.05)$ but with less-than-expected brain volume for size of head $(p<0.05)$ and larger VBR\% $(p<0.05)$, i.e. small head and evidence of atrophy.

Hemisphere diffusivity differences. The presence of a particular side with predominant injury, usually the right, at the time of acute ictus seems to affect white matter in that hemisphere some years later. For example, MANOVA with hemisphere diffusivity eigenvalues $\left(\lambda_{1}, \lambda_{2}, \lambda_{3}\right)$ shows that participant grouping has a significant main effect (Wilk's $\lambda 0.54, \mathrm{~F}$ $10.12, p=0.0006)$, and there is an interaction between participant grouping and side with injury (Wilk's $\lambda 0.58, F 2.86$, $p=0.047$ ). In Table 3, the follow-up ANOVA shows that right and left hemisphere mean diffusivity eigenvalues are similar for two groups but are different $(p<0.05)$ in the ICP subgroup with VBM-identified tissue abnormality. In this subgroup, both left and right hemispheres differ from the rest of the study

Table 1. Demographic and clinical features of subjects with tissue difference identified using voxel-based morphometry

\begin{tabular}{|c|c|c|c|c|c|c|c|}
\hline \multicolumn{3}{|c|}{ Patient } & \multicolumn{2}{|c|}{ Injury } & \multicolumn{3}{|c|}{ Acute imaging } \\
\hline $\begin{array}{c}\text { Sex } \\
(\mathrm{M} / \mathrm{F})\end{array}$ & $\begin{array}{l}\text { Age at accident } \\
\text { (years) }\end{array}$ & $\begin{array}{l}\text { Age at study } \\
\text { (years) }\end{array}$ & GCS & Mechanism & Hemorrhage & Fracture & Edema \\
\hline 1. $\mathrm{M}$ & 15.69 & 18.27 & 6 & Pedestrian & $\mathrm{L}$ thin subdural & No & L hemisphere \\
\hline 2. F & 13.02 & 21.06 & 8 & Pedestrian & $\mathrm{R}$ frontal lobe hemorrhage & $\mathrm{R}$ frontal & Diffuse \\
\hline 3. F & 11.10 & 16.74 & 3 & Pedestrian & $\mathrm{L}$ frontal contusion & $\mathrm{L}$ frontal & Diffuse \\
\hline 4. $\mathrm{M}$ & 13.02 & 15.83 & 5 & Fall $\sim 7 \mathrm{~m}$ & $\mathrm{R}$ temporal contusion & $\mathrm{R}$ temporal & $\mathrm{R}$ hemisphere \\
\hline 5. F & 8.44 & 14.27 & 6 & Fall $\sim 7 \mathrm{~m}$ & $\mathrm{R}$ subdural & R occipital & Diffuse \\
\hline 6. F & 12.79 & 16.40 & 7 & Cyclist & Bilateral $(\mathrm{L}>\mathrm{R})$ contusion & No & Diffuse \\
\hline 7. F & 12.18 & 22.17 & 4 & Cyclist & R subdural-Surgery needed & $\mathrm{R}$ temporal & $\mathrm{R}$ hemisphere \\
\hline 8. F & 2.73 & 8.93 & 6 & Passenger & R subarachnoid & $\mathrm{R}$ temporal & $\mathrm{R}$ more than $\mathrm{L}$ \\
\hline
\end{tabular}

Patients 2, 4, 6, 7 and 8 have periventricular distribution of differences identified on voxel-based morphometry.

Key: M male and F female; GCS, Glasgow coma score; L, left and R, right; and m, meters. 

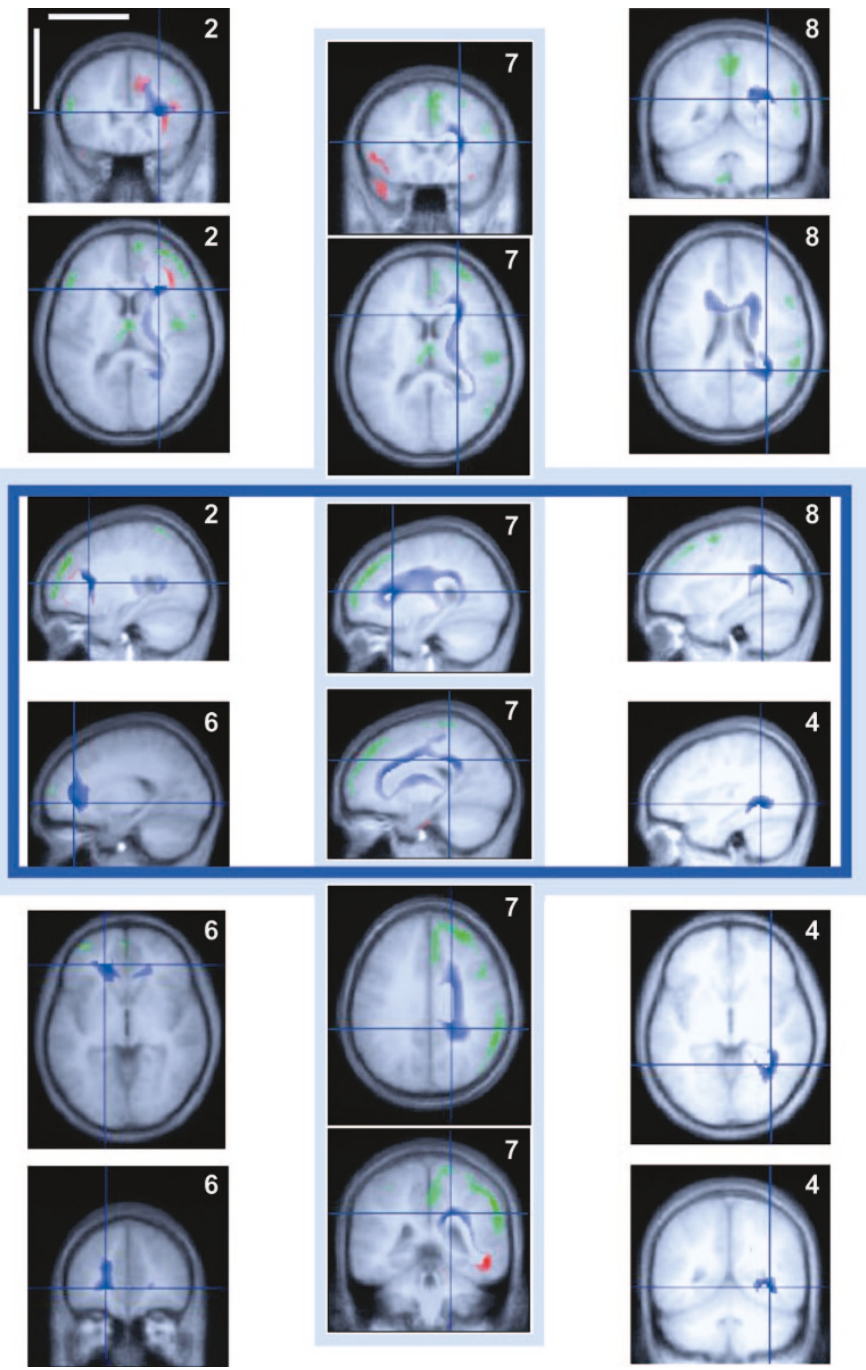

Figure 1. A composite of five cases in the VBM-identified group with periventricular white matter difference. Individual illustrations are displayed in neurologic convention with left hemisphere on the left. Each picture shows the statistical parametric maps (in red, blue, and green colors) superimposed on the mean normalized image of the group data, at a threshold of uncorrected $p<$ 0.001 . In comparison with the normalized image, blue indicates regions of white matter decrease, green indicates regions of grey matter decrease, and red indicates regions where white matter (probably gliosis) is increased. The central panel of six images shows the anteroposterior spectrum of periventricular white matter loss in the sagittal plane. Numbers (top right) correspond to participant numbers in Table 1. The white scale bars in the top left panel ( $x$ and $y$ axis) each represent $8 \mathrm{~cm}$.

participants $(p<0.05)$, with the right hemisphere showing more extreme difference than the left $(p<0.05)$.

Hippocampal volume and its relations. Figure 2 shows a case in which hippocampal atrophy is adjacent to periventricular white matter difference. In comparing all participants, right hippocampal volume corrected for hemisphere volume was smaller in the ICP subgroup with VBM-identified tissue loss ( $p$ $=0.011$; Table 4). There was no difference in corrected left hippocampal volume or in corrected left and right perihippocampal volumes. Multiple regression analysis with corrected right hippocampal volume as the response variable identified significant effects and interactions. The simple regressors tested included age at injury, age at follow-up, BSA, corrected right perihippocampal volume, corrected left hippocampal volume, and right hemisphere mean diffusivity eigenvalues. The main effects tested included gender, GCS, and ICP grouping. More than $93 \%$ of the variation in corrected right hippocampal volume is accounted for by only four parameters (whole-model test $F$ ratio is $9.09-11.97,0.0005<p<0.001$ ). These are, first, participant group $(F=9.87-11.99,0.003<p<0.005)$; second, an index of white matter change and predominant side with injury, right hemisphere diffusivity $\lambda_{1}(F=10.97, p=$ $0.009)$ or $\lambda_{2}(F=15.11, p=0.004)$ or $\lambda_{3}(F=16.85, p=$ 0.003 ); third, an index of global cerebral change (growth disturbance or atrophy), corrected left hippocampal volume ( $F$ $=10.63-13.74,0.005<p<0.01)$; and last, an index of severity of injury, GCS score at ictus $(F=3.61-5.04,0.12<$ $p<0.035$ ).

\section{DISCUSSION}

This study suggests that severe TBI with intracranial hypertension in childhood affects both postictal brain growth and cerebral morphology. These phenomena seem to be distinct because, first, there is an association between a longer time course of ictus ( $>3 \mathrm{~d})$ and later differences in OFC. Second, there is a subgroup with coexistent white matter difference and disproportionate hippocampal atrophy, which are more severe on the side with predominant injury.

Before discussing these points, some consideration should be given to possible limitations of this study. There may have been unavoidable bias in recruitment. It is possible that those with more severe outcome in the ICP group and those with better outcome in the non-ICP group were more inclined to volunteer for research. Hence, the differences may reflect an extreme case, rather than give a more general message about such a population. There is no evidence to support or refute this criticism-although it is unclear why such a bias might occur-but any differences in case-mix (e.g. age, gender, GCS, follow-up interval) have been incorporated in the statistical methods. Second, this is a cross-sectional study. Direct effects or changes were not measured but inferred from differences between groups. To determine change a longitudinal study is required. Last, these data have not been compared with normals; rather, a dose effect between groups has been sought. It is possible that all of the participants in this report exhibit some abnormality as a consequence of severe TBI in childhood, and a significant morphologic difference may have been missed (e.g. bilateral hippocampal or perihippocampal damage). However, normal anthropometry values in the less severe participants might well exclude this possibility.

Head disproportion and brain growth. There is $\sim 1 \mathrm{SD}$ difference in head circumference between the groups, with disproportionately smaller heads in those with severe TBI and intracranial hypertension. Inspection of OFC reference data (12) indicates that at the age of $\sim 15 \mathrm{y}$-the average age in this study -1 SD difference is equivalent to $\sim 5$ y previous head growth. Given that the interval between acute ictus and follow-up was almost $5 \mathrm{y}$, this suggests that in those with severe TBI and intracranial hypertension, there may have been significant limitation in head growth in the intervening period. 
Table 2. Anthropometry and cerebral morphometry

\begin{tabular}{|c|c|c|c|c|c|}
\hline & \multicolumn{3}{|c|}{ Patient Grouping } & \multicolumn{2}{|c|}{ ANOVA } \\
\hline & \multirow[b]{2}{*}{$\begin{array}{l}\text { Non-ICP Mean } \\
\text { (SD) }\end{array}$} & \multicolumn{2}{|c|}{ ICP } & \multirow[b]{2}{*}{$\mathrm{F}$} & \multirow[b]{2}{*}{$p$} \\
\hline & & $\begin{array}{l}\text { No VBM } \\
\text { tissue loss Mean } \\
\text { (SD) }\end{array}$ & $\begin{array}{c}\text { VBM } \\
\text { tissue loss Mean } \\
\text { (SD) }\end{array}$ & & \\
\hline Anthropometry & $\mathrm{n}=10$ & $\mathrm{n}=15$ & $\mathrm{n}=8$ & & \\
\hline Body mass index (SDS) & $0.31(1.00)$ & $0.36(0.88)$ & $0.33(0.99)$ & 0.01 & 0.99 \\
\hline Brain morphometry & $\mathrm{n}=8$ & $\mathrm{n}=15$ & $\mathrm{n}=7$ & & \\
\hline Brain-corrected $\left(\mathrm{cm}^{3}\right)$ & $1413.00(106.69)$ & $1446.14(119.64)$ & $1263.62(57.67)^{\mathrm{b}, \mathrm{c}}$ & 8.20 & 0.002 \\
\hline $\mathrm{VBR} \%$ & $1.14(0.52)$ & $1.16(0.34)$ & $2.98(2.15)^{\mathrm{b}, \mathrm{c}}$ & 7.45 & 0.003 \\
\hline Left brain-corrected $\left(\mathrm{cm}^{3}\right)$ & $744.45(53.54)$ & $745.34(66.63)$ & $663.86(39.43)^{\mathrm{b}, \mathrm{c}}$ & 6.07 & 0.006 \\
\hline Right brain-corrected $\left(\mathrm{cm}^{3}\right)$ & $710.77(57.57)$ & $723.81(53.48)$ & $626.59(35.46)^{\mathrm{b}, \mathrm{c}}$ & 9.98 & 0.0005 \\
\hline
\end{tabular}

Post hoc testing taking account of multiple comparisons $(p<0.05)$ : ${ }^{\mathrm{a}}$ non-ICP group versus ICP sub-group with no VBM-identified tissue loss; ${ }^{\mathrm{b}}$ non-ICP group versus ICP sub-group with VBM-identified tissue loss; ${ }^{\mathrm{c}}$ ICP sub-group with no VBM-identified tissue loss versus patients with VBM-identified tissue loss.

Key: ICP, intracranial pressure; VBM, voxel-based morphometry; OFC, occipitofrontal head circumference; and SDS, standard deviation score.

Table 3. Left and right hemisphere mean diffusivity eigenvalues

\begin{tabular}{|c|c|c|c|c|c|}
\hline & \multicolumn{3}{|c|}{ Patient Grouping } & \multicolumn{2}{|c|}{ ANOVA } \\
\hline & $\begin{array}{c}\text { Non-ICP } \\
\text { Mean (SD) }\end{array}$ & $\begin{array}{l}\text { No VBM } \\
\text { tissue loss } \\
\text { Mean (SD) }\end{array}$ & $\begin{array}{c}\text { VBM } \\
\text { tissue loss } \\
\text { Mean (SD) }\end{array}$ & $\mathrm{F}$ & $p$ \\
\hline Mean diffusivity & $\mathrm{n}=9$ & $\mathrm{n}=14$ & $\mathrm{n}=5$ & & \\
\hline \multicolumn{6}{|c|}{ Left hemisphere eigenvalues } \\
\hline$\lambda_{1}$ & $1.01(0.05)$ & $1.03(0.08)$ & $1.17(0.12)^{\mathrm{a}, \mathrm{b}}$ & 6.30 & 0.006 \\
\hline \multicolumn{6}{|c|}{ Right hemisphere eigenvalues } \\
\hline$\lambda_{3}$ & $0.54(0.03)$ & $0.57(0.05)$ & $0.81(0.31)^{\mathrm{a}, \mathrm{b}}$ & 8.00 & 0.002 \\
\hline$\lambda_{2}$ & $0.72(0.04)$ & $0.75(0.04)$ & $1.00(0.34)^{\mathrm{a}, \mathrm{b}}$ & 7.47 & 0.003 \\
\hline$\lambda_{1}$ & $1.01(0.05)$ & $1.04(0.06)$ & $1.30(0.36)^{\mathrm{a}, \mathrm{b}}$ & 6.38 & 0.006 \\
\hline
\end{tabular}

Post hoc testing taking account of multiple comparisons $(p<0.05):{ }^{\text {a }}$ non-ICP group versus ICP sub-group with VBM-identified tissue loss; ${ }^{\mathrm{b}}$ ICP sub-group with no VBM-identified tissue loss versus patients with VBM-identified tissue loss.

Key: ICP, intracranial pressure; VBM, voxel-based morphometry.

This conclusion is in keeping with previously reported lack of change in corpus callosum area 3 y after head injury in childhood (28)—although no anthropometry observations were supplied with that report, so direct comparisons are not possible.

One explanation may be that injury was severe enough to cause cerebral atrophy $(29,30)$. However, in a major proportion of the ICP group, there was no evidence of cerebral atrophy (i.e. brain volume was appropriate for head circumference, and there was no increase in ventricular brain ratio). Alternatively, trauma may have resulted in long-term neuroendocrinologic deficiencies such that postictal growth was impaired (31). However, growth failure in height is usually a prominent feature, and this was not present here. Last, the potential for adolescent brain growth $(7,32)$ may have been adversely affected by severe TBI with raised ICP or by our medical management of that state, occurring at a critical stage of preadolescent brain development. For example, the temporal lobe, which is particularly vulnerable to mechanical deformation (33), and injury in children (34) has accretion of grey matter continuing until the age of $\sim 16.5 \mathrm{y}$ (7).
Cerebral atrophy and white matter architecture. Wholebrain VBM demonstrated tissue difference in eight participants who also had evidence of atrophy and different white matter architecture. Ventricular dilation in children $(35,36)$ and adults $(37,38)$ with severe brain injury is an indicator of parenchymal loss, more sensitive to periventricular white matter change than grey. In adults, a slow decrease in brain volume has been reported (39), occurring up to $3 \mathrm{y}$ after injury with volume loss at a rate greater than that seen with normal aging. None of our participants had symptomatic hydrocephalus, either acute or normal pressure variant. Hence, given that all eight participants with VBM-identified difference had focal hemorrhage and associated hemisphere edema, combined periventricular and hemisphere differences may result from regional perfusion failure $(40,41)$ and secondary axonal degeneration in the hemisphere subjacent to or involved in hemorrhage (42).

Regional hippocampal vulnerability and direct injury. Disproportionate hippocampal growth disturbance or atrophy was not found in the subgroup of ICP participants without VBMidentified tissue loss. Neither was it seen in the left hemisphere (usually the one contralateral to predominant injury) in indi- 


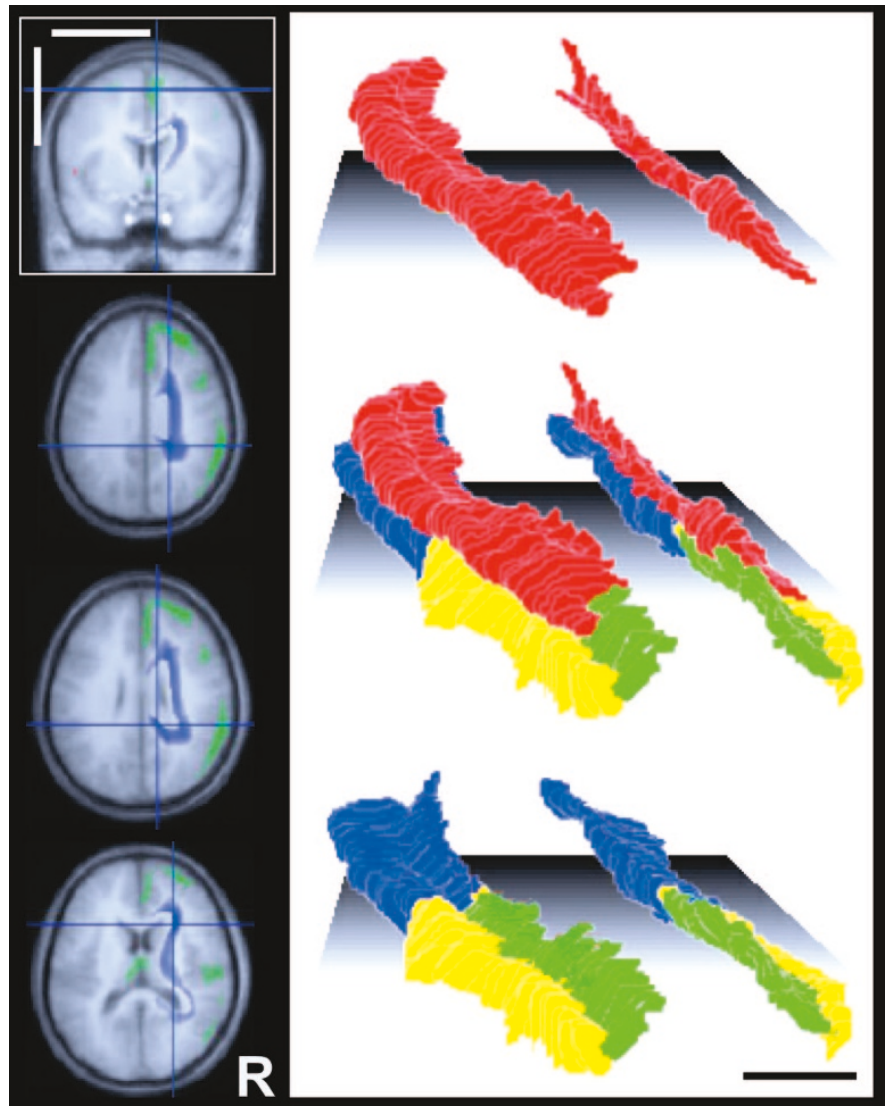

Figure 2. A summary of images from an adult who sustained severe brain injury in childhood showing right periventricular white matter loss and right hippocampal atrophy. (Left) A composite of statistical parametric maps (blue and green colors) superimposed on the mean normalized image of the group data, at a threshold of uncorrected $p<0.001$. In comparison with the normalized image, blue indicates regions of white matter decrease and green indicates regions of grey matter decrease. The white scale bars in the top left panel ( $x$ and $y$ axis) each represent $8 \mathrm{~cm}$. (Right) Perihippocampal volumetric reconstruction with red indicating the hippocampus, green indicating the entorhinal area, yellow indicting the perirhinal area, and blue indicating the parahippocampal area. Individual slices have been overlaid to show the extent of atrophy. The black scale bar (bottom right) represents $2 \mathrm{~cm}$ in the $x-y$ plane.

viduals with VBM loss, even though there was evidence of that hemisphere's exhibiting a difference in white matter diffusivity. Rather, in the right hemisphere, disproportionately small hippocampal volume was related to factors that reflected the severity of initial ictus and change in white matter. There was no association with perihippocampal volume, which was surprising given the specific vulnerability of the parahippocampal gyrus to intracranial hypertension above $20 \mathrm{~mm} \mathrm{Hg} \mathrm{(43).}$ Hence, our conclusion is that these findings are consistent with those in adults (i.e. the importance of severity of primary injury and subsequent white matter effects) $(4,5)$. The current findings are also in keeping with the previous report in children (6) that indicated a trend toward smaller right hippocampal volume after TBI. The current study extends these findings. First, in children, hippocampal abnormality is not attributable to an isolated loss of growth potential, as atrophy was not seen in the "growth disturbance" ICP subgroup. Second, the data highlight the importance of impact of acute injury to hippocampal abnormality. Last, any association between hippocampal vulnerability and systemic metabolic insult or raised ICP seem to be unlikely as hippocampal findings were not bilateral and there was no associated loss of perihippocampal volume (43).

Taken together-head circumference and cerebral and hippocampal volume after TBI in childhood-the relationships in this report suggest, first, that during the acute ictus, there is some reduction in threshold for pathology in the hemisphere ipsilateral to injury. We can only speculate on the substrate for this alteration, but an interaction between systemic and local cerebral inflammatory mechanisms is suggested in the recent literature (44). Second, during development after TBI, there may be long-term effects on potential growth and white matter microarchitecture. We note that in the current series, the difference in head size after TBI is of the order that is associated with lesser performance and cognitive function in late adulthood $(1,2)$. Hence, we believe that these findings provide useful data of additional value when considering the lifelong evolution of functional and behavioral outcome after TBI in childhood.

Acknowledgments. We thank Debbie White and Vicki Lupson (Addenbrooke's Hospital and the Wolfson Brain Imaging Centre, Cambridge) and Dr. Mortimer Miskin (National Institute of Mental Health, Bethesda, MD) for help with hippocampal and perihippocampal morphometry.

Table 4. Corrected left and right hippocampal and peri-hippocampal volumes

\begin{tabular}{|c|c|c|c|c|c|}
\hline & \multicolumn{3}{|c|}{ Patient Grouping } & \multicolumn{2}{|c|}{ ANOVA } \\
\hline & \multirow[b]{2}{*}{$\begin{array}{c}\text { Non-ICP } \\
\text { Mean (SD) }\end{array}$} & \multicolumn{2}{|c|}{ ICP } & \multirow[b]{2}{*}{$\mathrm{F}$} & \multirow[b]{2}{*}{$p$} \\
\hline & & $\begin{array}{l}\text { No VBM } \\
\text { tissue loss } \\
\text { Mean (SD) }\end{array}$ & $\begin{array}{c}\text { VBM } \\
\text { tissue loss } \\
\text { Mean (SD) }\end{array}$ & & \\
\hline Regional volumes & $\mathrm{n}=8$ & $\mathrm{n}=13$ & $\mathrm{n}=7$ & & \\
\hline \multicolumn{6}{|l|}{ Corrected volumes $\left(\mathrm{cm}^{3}\right)$} \\
\hline Right hippocampus & $3.33(0.44)$ & $3.03(0.29)$ & $2.56(0.63)^{\mathrm{a}, \mathrm{b}}$ & 5.49 & 0.011 \\
\hline Right peri-hippocampal & $4.38(0.49)$ & $3.95(0.85)$ & $3.83(1.38)$ & 0.53 & 0.60 \\
\hline
\end{tabular}

Post hoc testing taking account of multiple comparisons $(p<0.05)$ : ${ }^{\text {a }}$ non-ICP group versus ICP sub-group with VBM-identified tissue loss; ${ }^{\mathrm{b}}$ ICP sub-group with no VBM-identified tissue loss versus patients with VBM-identified tissue loss.

Key: ICP, intracranial pressure; VBM, voxel-based morphometry. 


\section{REFERENCES}

1. Gale CR, O'Callaghan FJ, Godfrey KM, Law CM, Martyn CN 2004 Critical periods of brain growth and cognitive function in children. Brain 127:321-329

2. Gale CR, Walton S, Martyn CN 2003 Foetal and postnatal head growth and risk of cognitive decline in old age. Brain 126:2273-2278

3. Kraus JF, Rock A, Hemyari P 1990 Brain injuries among infants, children, adolescents, and young adults. Am J Dis Child 144:684-691

4. Tate DF, Bigler ED 2000 Fornix and hippocampal atrophy in traumatic brain injury. Learn Mem 7:442-446

5. Bigler ED, Anderson CV, Blatter DD 2002 Temporal lobe morphology in normal aging and traumatic brain injury. AJNR Am J Neuroradiol 23:255-266

6. Di Stefano G, Bachevalier J, Levin HS, Song JX, Scheibel RS, Fletcher JM 2000 Volume of focal brain lesions and hippocampal formation in relation to memory function after closed head injury in children. J Neurol Neurosurg Psychiatry 69:210 216

7. Giedd JN, Blumenthal J, Jeffries NO, Castellanos FX, Liu H, Zijdenbos A, Paus T, Evans AC, Rapoport JL 1999 Brain development during childhood and adolescence: a longitudinal MRI study. Nat Neurosci 2:861-863

8. Ng T, Graham DI, Adams JH, Ford I 1989 Changes in the hippocampus and the cerebellum resulting from hypoxic insults: frequency and distribution. Acta Neuropathol (Berl) 78:438-443

9. Teasdale G, Jennett B 1974 Assessment of coma and impaired consciousness. A practical scale. Lancet 2:81-84

10. Tasker RC 2001 Neurocritical care and traumatic brain injury. Indian J Pediatr 68:257-266

11. Child Growth Foundation 1996 Growth Charts. Child Growth Foundation, London

12. Freeman JV, Cole TJ, Chinn S, Jones PR, White EM, Preece MA 1995 Cross sectional stature and weight reference curves for the UK, 1990. Arch Dis Child 73:17-24

13. Coulthard MG 1994 Surface area is best estimated from weight alone: pocket calculators and nomograms are unnecessary. Arch Dis Child 71:281

14. Stejskal EO, Tanner JE 1965 Spin diffusion measurements: spin-echoes in the presence of a time-dependent field gradient. J Chem Phys 42:288-292

15. Papadakis NG, Xing D, Huang CL, Hall LD, Carpenter TA 1999 A comparative study of acquisition schemes for diffusion tensor imaging using MRI. J Magn Reson 137:67-82

16. Xing D, Papadakis NG, Huang CL, Lee VM, Carpenter TA, Hall LD 1997 Optimized diffusion-weighting for measurement of apparent diffusion coefficient (ADC) in human brain. Magn Reson Imaging 15:771-784

17. Jezzard P, Barnett AS, Pierpaoli C 1998 Characterization of and correction for eddy current artefacts in echo planar diffusion imaging. Magn Reson Med 39:801-812

18. Papadakis NG, Martin KM, Pickard JD, Hall LD, Carpenter TA, Huang CL 2000 Gradient preemphasis calibration in diffusion weighted echo-planar imaging. Magn Reson Med 44:616-624

19. Van Paesschen W, Connelly A, King MD, Jackson GD, Duncan JS 1997 The spectrum of hippocampal sclerosis: a quantitative magnetic resonance imaging study. Ann Neurol 41:41-51

20. Giedd JN, Rumsey JM, Castellanos FX, Rajapakse JC, Kaysen D, Vaituzis AC, Vauss YC, Hamburger SD, Rapoport JL 1996 A quantitative MRI study of the corpus callosum in children and adolescents. Brain Res Dev Brain Res 91:274-280

21. Dalton CM, Brex PA, Jenkins R, Fox NC, Miszkiel KA, Crum WR, O'Riordan JI, Plant GT, Thompson AJ, Miller DH 2002 Progressive ventricular enlargement in patients with clinically isolated syndromes is associated with the early development of multiple sclerosis. J Neurol Neurosurg Psychiatry 73:141-147

22. Blatter DD, Bigler ED, Gale SD, Johnson SC, Anderson CV, Burnett BM, Parker N, Kurth S, Horn SD 1995 Quantitative volumetric analysis of brain MR: normative database spanning 5 decades of life. AJNR Am J Neuroradiol 16:241-251

23. Van Hoesen GW 1982 The parahippocampal gyrus. Trends Neurosci 5:345-350
24. Ashburner J, Friston KJ 2000 Voxel-based morphometry-the methods. Neuroimage 11:805-821

25. Ashburner J, Neelin P, Collins DL, Evans A, Friston K 1997 Incorporating prior knowledge into image registration. Neuroimage 6:344-352

26. Salmond CH, Ashburner J, Vargha-Khadem F, Connelly A, Gadian DG, Friston KJ 2002 Distributional assumptions in voxel-based morphometry. Neuroimage 17:10271030

27. Basser PJ, Mattiello J, LeBihan D 1994 Estimation of the effective self-diffusion tensor from the NMR spin echo. J Magn Reson B 103:247-254

28. Levin HS, Benavidez DA, Verger-Maestre K, Perachio N, Song J, Mendelsohn DB, Fletcher JM 2000 Reduction of corpus callosum growth after severe traumatic brain injury in children. Neurology 54:647-653

29. Tomita H, Ito U, Saito J, Maehara T 1990 Cerebral atrophy after severe head injury. Adv Neurol 52:553

30. Onuma T, Shimosegawa Y, Kameyama M, Arai H, Ishii K 1995 Clinicopathologica investigation of gyral high density on computerized tomography following severe head injury in children. J Neurosurg 82:995-1001

31. Lopez Guzman A, Salvador J, Albero R, Sastre J, Iglesias P, Diez JJ, Gomez-Pan A 1992 Selective growth hormone deficiency of hypothalamic origin following severe head injury. Acta Paediatr 81:698-699

32. Sowell ER, Thompson PM, Holmes CJ, Jernigan TL, Toga AW 1999 In vivo evidence for post-adolescent brain maturation in frontal and striatal regions. Nat Neurosci 2:859-861

33. Adams JH, Graham DI, Gennarelli TA 1985 Contemporary neuropathological considerations regarding brain damage in head injury. In: Becker DP, Povlishock JT (eds) Central Nervous System Trauma Status Report. National Institutes of Health, Washington, DC, pp 65-87

34. Mendelsohn D, Levin HS, Bruce D, Lilly M, Harward H, Culhane KA, Eisenberg HM 1992 Late MRI after head injury in children: relationship to clinical features and outcome. Childs Nerv Syst 8:445-452

35. Henry-Feugeas MC, Azouvi P, Fontaine A, Denys P, Bussel B, Maaz F, Samson Y, Schouman-Claeys E 2000 MRI analysis of brain atrophy after severe closed-head injury: relation to clinical status. Brain Inj 14:597-604

36. Verger K, Junque C, Levin HS, Jurado MA, Perez-Gomez M, Bartres-Faz D, Barrios M, Alvarez A, Bartumeus F, Mercader JM 2001 Correlation of atrophy measures on MRI with neuropsychological sequelae in children and adolescents with traumatic brain injury. Brain Inj 15:211-221

37. Levin HS, Meyers CA, Grossman RG, Sarwar M 1981 Ventricular enlargement after closed head injury. Arch Neurol 38:623-629

38. Cullum CM, Bigler ED 1986 Ventricle size, cortical atrophy and the relationship with neuropsychological status in closed head injury: a quantitative analysis. J Clin Exp Neuropsychol 8:437-452

39. Blatter DD, Bigler ED, Gale SD, Johnson SC, Anderson CV, Burnett BM, Ryser D, Macnamara SE, Bailey BJ 1997 MR-based brain and cerebrospinal fluid measurement after traumatic brain injury: correlation with neuropsychological outcome. AJNR Am J Neuroradiol 18:1-10

40. De Reuck J 1971 The human periventricular arterial blood supply and the anatomy of cerebral infarctions. Eur Neurol 5:321-334

41. Moody DM, Bell MA, Challa VR 1990 Features of the cerebral vascular pattern that predict vulnerability to perfusion or oxygenation deficiency: an anatomic study. AJNR Am J Neuroradiol 11:431-439

42. Duhaime AC, Gennarelli LM, Yachnis A 1994 Acute subdural haematoma: is the blood itself toxic? J Neurotrauma 11:669-678

43. Adams JH, Graham DI 1976 The relationship between ventricular fluid pressure and the neuropathology of raised intracranial pressure. Neuropathol Appl Neurobiol $2: 323-332$

44. Campbell SJ, Hughes PM, Iredale JP, Wilcockson DC, Waters S, Docagne F, Perry VH, Anthony DC 2003 CINC-1 is an acute-phase protein induced by focal brain injury causing leukocyte mobilization and liver injury. FASEB J 17:1168-1170 